\title{
Kinetic Behaviour of Pancreatic Lipase Inhibition by Ultrasonicated $A$. malaccensis and $A$. subintegra Leaves of Different Particle Sizes
}

\author{
Miradatul Najwa Muhd Rodhi*, Fazlena Hamzah, Ku Halim Ku Hamid \\ Faculty of Chemical Engineering, Universiti Teknologi MARA (UiTM), 40450 Shah Alam, Selangor, \\ Malaysia.
}

Received: $4^{\text {th }}$ September 2020; Revised: $1^{\text {st }}$ November 2020; Accepted: $2^{\text {nd }}$ November 2020; Available online: $9^{\text {th }}$ November 2020; Published regularly: December 2020

\begin{abstract}
Gallic acid and quercetin equivalent were determined in the crude extract of matured leaves Aquilaria malaccensis and Aquilaria subintegra. The leaves of both Aquilaria species were dried at $60{ }^{\circ} \mathrm{C}$ for 24 hours, ground and sieved into particle size of $250,300,400,500$, and $1000 \mu \mathrm{m}$. Then, each particle size of leaves was soaked in distilled water with a ratio of $1: 100(\mathrm{w} / \mathrm{v})$ for 24 hours and undergoes the pretreatment method by using ultrasonicator $(37 \mathrm{kHz})$, at the temperature of $60{ }^{\circ} \mathrm{C}$ for 30 minutes. The crude extracts were obtained after about 4 hours of hydrodistillation process. The highest concentration of gallic acid and quercetin equivalent was determined in the crude extract from the particle size of $250 \mu \mathrm{m}$. The kinetics of pancreatic lipase inhibition was further studied based using the LineweaverBurk plot, wherein the concentration of $p$-NPP as the substrate and pancreatic lipase were varied. Based on the formation of the lines in the plot, the crude leaves extract of both Aquilaria species exhibit the mixed-inhibition on pancreatic lipase, which indicates that in the reaction, the inhibitors were not only attached to the free pancreatic lipase, but also to the pancreatic lipase-( $p$-NPP) complex. The reaction mechanism was similar to non-competitive inhibition; however the value of dissociation constant, $K_{i}$, for both inhibition pathways was different. The inhibition shows an increment in Michaelis Menten constant $\left(K_{m}\right)$ and a reduction in the maximum pancreatic lipase activity $\left(V_{m}\right)$ compared to the reaction without Aquilaria spp. crude extracts (control). This proved that the inhibition occurred in this reaction. Copyright $\odot 2020$ BCREC Group. All rights reserved
\end{abstract}

Keywords: Aquilaria; Gallic acid; Kinetic inhibition; Pancreatic Lipase; Quercetin

How to Cite: Rodhi, M.N.M., Hamzah, F., Hamid, K.H.K. (2020). Kinetic Behaviour of Pancreatic Lipase Inhibition by Ultrasonicated A. malaccensis and A. subintegra Leaves of Different Particle Sizes. Bulletin of Chemical Reaction Engineering \& Catalysis, 15(3), 818-828

(doi:10.9767/bcrec.15.3.8864.818-828)

Permalink/DOI: https://doi.org/10.9767/bcrec.15.3.8864.818-828

\section{Introduction}

The issue of obesity and weight gain has become a priority now as it involves a person's level of health, from which critical illnesses can

\footnotetext{
* Corresponding Author.

Email:miradatul@uitm.edu.my (M.N.M. Rodhi);

Telp: +603-55436488, Fax: +603-55436300
}

stem from these problems. The prevalence of obesity and weight gain related diseases has encouraged various research institutions and biopharmaceutical companies to study and produce the weight-loss drugs. However, the demand for natural medicine is higher than chemical-based materials because awareness of the dangers and side effects that will be encountered. Hence, the needs for further development of weight-loss 
and obesity natural products are becoming more and more urgent. Nowadays, people are more concerned about the fat content in their body because for them, this is a major cause towards obesity and weight gain. Due to this matter, pancreatic lipase inhibitors have received more and more attention, since pancreatic lipase is a digestive enzyme produced by stomach and pancreas, which primarily function to break down fats into smaller molecules that can be easily absorbed and digested by intestines. Nevertheless, in theory, too much pancreatic lipase activity could be irritating because it could lead to obesity.

Alternatives found to slow down this enzyme activity is by taking the synthetic inhibitors such as anti-obesity drugs which have been deeply studied over decades. Last 13 years ago, FDA has approved four weight loss drugs which are Orlistat, Contrive, Belviq and Qsymia. There are only three drugs were approved by the FDA as adjunctive therapy for chronic weight management which are Orlistat that was approved in 1999, Belviq and Qsymia, both were approved in 2012 [1]. These clinical medications manipulate body weight by increasing energy expenditure, suppressing appetite, or inhibiting pancreatic lipase to decrease lipid absorption in the intestine [2]. Thus, as of September 2013, only Orlistat that has been approved by FDA and EMA (European Medicines Agency) for chronic weight management which able to inhibit gastrointestinal lipases in reducing fat absorption and it became the only FDA-approved weight loss drug that is available without a prescription [3]. The drugs are potential to decrease weight but possible side effects are always a big public health concern in new drug product development. However, Orlistat has a number of safety issues, including hepatotoxicity, nephrotoxicity, pancreatitis, kidney stones and the most common adverse effect is steatorrhea [3]. The risks also include severe liver damage, acute pancreatitis, acute renal failure, and pre-cancerous colon lesions. Other than that, Orlistat also interfere the fatsoluble vitamin absorption, which could cause a transient vitamin A, D, E, or K deficiency [4]. As conclusion, due to the modest efficacy, undesirable adverse effects, and serious health risks given by orlistat has highlighted the lacks of using Orlistat which later emphasizing the needs for other obesity drug options.

Therefore, traditional herbal medicines were believed in being able to suppress appetite and promote weight loss. These natural materials could be relatively more economical with no toxic side effects when compared with the synthetic drugs. Natural products have potential in the treatment of obesity and it is still largely unexplored [5]. By exploring the potential of Aquilaria sp., it might be an excellent alternative strategy for the development of safe and effective obesity control therapies. World Health Organization (WHO) declares that about 20000 plants are used for medical purposes and over $80 \%$ of world's population are using them for their primary health care [6]. This can be seen from the previous studies that explored anti-obesity compounds derived from green, white and black tea leaves which later become very popular functional food to be consumed [7]. There were findings proven that strong pancreatic lipase inhibitory activity were obtained for the in-vitro anti-lipase and antioxidant assays using crude ethanolic extracts from 30 plants grown in Oaxaca, México [8]. Strong inhibition of pancreatic lipase and pancreatic cholesterol esterase activities, as well as the inhibition of cholesterol micelle formation, and bile acid binding was also was proven by using mulberry leaf extract [9]. Thus, the results obtained by researchers proven that plant is able to help in controlling obesity.

Plant-derived lipase inhibitors have become potential research hotspots compared with chemically synthesized lipase inhibitors. Although it is difficult to determine the active components in the plant-based product sell in the market, but for consumer this product is relatively cheap, safe and reliable and known to be an effective slimming product, which makes the plant-based product is in demand. Therefore, this research explored the potential of two Aquilaria sp. namely A. malaccensis and A. subintegra as the pancreatic lipase inhibitor. Moreover, as up-to-date, it is nowhere to be found any studies on these species as the inhibitor for pancreatic lipase. The crude extract was obtained from hydrodistillation of ultrasonicated $A$. subintegra and A. malaccensis leaves for different particle size of 250, 300, 400, 500, and $1000 \mu \mathrm{m}$. Prior to extraction process, soaking and ultrasonication methods were introduced because it were claimed by most of researchers that both soaking and ultrasonication process were found to increase the specific surface area of the prepared samples while decreasing the average particle size and enhanced the yield of gallic acid and quercetin produced during extraction process [10-12]. The content of gallic acid and quercetin equivalent in the crude extracts were deter- 
mined and the inhibitory studies were done.

Research on lipase inhibition by plant-based products has widely done and some of the research shows obvious inhibitory effects [13]. Yet, due to the low content of active ingredients, complicated in extraction procedures and low recovery rate, which make it cannot be produced in large quantities. Consequently, only few of them had undergo the clinical stage. This is a major drawback in commercialization of lipase inhibitors derived from edible plants. One of the suggestion is to study the action mechanism of natural compounds on pancreatic lipase, while the high-activity pancreatic lipase inhibitors are still continuously screened [13]. Thus, this research also emphasis on the reaction mechanism in inhibition of pancreatic lipase by $A$. malaccensis and A. subintegra leaves crude extract, wherein the activity of pancreatic lipase inhibitor was determined throughout the reaction. This research is one of the fundamental works for future studies on the natural obesity treatment, which is a new direction of the key research in the lipase inhibition mechanism field. It is also expected that the scientific data obtained would be beneficial towards the global development of agricultural and healthcare.

\section{Materials and Methods}

\subsection{Drying, Milling, Sieving and Pretreatment} of Leaves

The matured leaves of $A$. malaccensis and $A$. subintegra were collected from a farm in Selangor. The leaves were washed thoroughly and left to dry at room temperature before being dried in the oven (Memmert) at $60{ }^{\circ} \mathrm{C}$ for 24 hours. The dried leaves were milled by using Mastar (MAS-160BL (A)-1) blender to obtain fine powder. Next, the ground leaves were sieved into uniform particle sizes of powdered leaves at $250,300,400,500$ and $1000 \mu \mathrm{m}$. Then, each of particle size of A. malaccensis and A. subintegra powdered leaves were soaked for 24 hours in distilled water with a ratio of 1:100 (w/v) at room temperature. After soaking process, all particle sizes of leaves were ultrasonicated in a NEXXsonics NS-A-18H ultrasonicator. This pretreatment process was done at 30 minutes for each sample with a frequency of $37 \mathrm{kHz}$ at $60{ }^{\circ} \mathrm{C}$.

\subsection{Hydrodistillation of Crude Extract}

The pre-treated A. malaccensis and A. subintegra leaves was hydrodistilled by using a TOPS MS-6 heating mantle at constant atmos- pheric pressure and at $70{ }^{\circ} \mathrm{C}$ until a sufficient amount of hydrodistillate was obtained (basically in a range of 300 to $400 \mathrm{~mL}$ ). Then, the extracted leaves were evaporated under reduced pressure at $40{ }^{\circ} \mathrm{C}$ to get a concentrated product by using a Heidolph rotary evaporator. The crude leaves extract was kept in the refrigerator for further analysis and experiment in order to prevent any microbe from breeding through the samples.

\subsection{Determination of Total Phenol Contents (TPC)}

The total phenolic content was determined by using Folin-Ciocalteau method [14-17]. The mixture of $0.2 \mathrm{~mL}$ of leaves extract and $0.2 \mathrm{~mL}$ of Folin-Ciocalteau reagent were left for 4 minutes, in order to allow the reaction before it was added with $1 \mathrm{~mL}$ of $15 \% \mathrm{Na}_{2} \mathrm{CO}_{3}$. After $\mathrm{Na}_{2} \mathrm{CO}_{3}$ was added, the mixture was allowed to stand for another 2 hours at room temperature. Then, the absorbance was measured at the wavelength of $760 \mathrm{~nm}$. The absorbance was then used to obtain the concentration of gallic acid equivalent, by using the equation of gallic acid calibration curve that was constructed from the absorbance and concentration of gallic acid in the dilutions prepared from gallic acid stock solution. The stock solution was prepared by dissolving $100 \mathrm{mg}$ of dry gallic acid in $2 \mathrm{~mL}$ of ethanol and diluted to volume with water in a $100-\mathrm{mL}$ volumetric flask. Dilutions of this stock solution were done to have a range of gallic acid concentration between 0 and $1 \mathrm{mg} / \mathrm{ml}$. The absorbance of each dilution solution was taken after Folin-Ciocalteu method was carried out and the plot of absorbance vs. gallic acid concentration was constructed. The results were expressed as $\mathrm{mg} / \mathrm{ml}$ of gallic acid equivalent (GE). All readings were triplicated and the average of the readings was taken.

\subsection{Determination of Total Flavonoid Contents (TFC)}

The content of total flavonoids was determined by using the aluminium chloride $\left(\mathrm{AlCl}_{3}\right)$ assay [18]. The amount of $0.5 \mathrm{~mL}$ of leaves extract, $0.1 \mathrm{~mL} 10 \% \mathrm{AlCl}_{3}, 0.1 \mathrm{~mL}$ of potassium acetate, and $4.3 \mathrm{~mL}$ of deionized water were mixed. Then, the mixture was incubated for 30 minutes at room temperature. The absorbance was then measured at the wavelength of 415 $\mathrm{nm}$ using spectrophotometer. The absorbance was then used to obtain the concentration of quercetin equivalent, by using the equation of quercetin calibration curve that was construct- 
ed from the absorbance and concentration of quercetin in the dilutions prepared from the quercetin stock solution. The stock solution was prepared by dissolving $100 \mathrm{mg}$ of dry quercetin in $2 \mathrm{~mL}$ of ethanol and diluted to volume with water in a $100 \mathrm{~mL}$ volumetric flask. Dilutions of this stock solution were done to have a range of quercetin concentration between 0 and 1 $\mathrm{mg} / \mathrm{mL}$. The absorbance of each dilution solution was determined by using the $\mathrm{AlCl}_{3}$ method and the plot of absorbance vs. quercetin concentration was constructed. The results were expressed as $\mathrm{mg} / \mathrm{ml}$ of quercetin equivalent (QE). All readings were triplicated and the average of the readings was taken.

\subsection{Pancreatic Lipase Inhibition Reaction}

Inhibition activity of pancreatic lipase was studied via spectrophotometric analysis [19,20]. Crude porcine pancreatic lipase (PPL) from Sigma (USA) was suspended in tris- $\mathrm{HCl}$ buffer ( $\mathrm{pH}$ 7.4) with $2.5 \mathrm{mmol} \mathrm{NaCl}$ to give a concentration of $200 \mathrm{U} / \mathrm{mL}$ of pancreatic lipase. Then, $p$-nitrophenyl palmitate ( $p$-NPP) was dissolved in water as pancreatic lipase substrate. Next, 1 $\mathrm{mL}$ of crude leaves extracts were mixed with 1 $\mathrm{mL}$ of enzyme suspension, $3 \mathrm{~mL}$ of substrate solution and $6 \mathrm{~mL}$ of tris- $\mathrm{HCl}$ buffer. The reaction was carried out in water bath at temperature of $37^{\circ} \mathrm{C}$ for 30 minutes. After the reaction, $1 \mathrm{~mL}$ of acetone and ethanol mixture at a ratio of $1: 1$ was added in order to stop the PPL activity. The absorbance was measured by using spectrophotometer at wavelength of $410 \mathrm{~nm}$. The absorbance was used to obtain the amount of $p$-nitrophenol ( $p$-NP) liberated by using the equation from $p$-NP calibration curve. The calibration curve was constructed from the absorbance and concentration of $p$-NP at the range from 0 to $1000 \mu \mathrm{mol} / \mathrm{mL}$. The readings were triplicated and averaged. The standard PPL activity which was without Aquilaria crude extract and the PPL activity of sample with Aquilaria crude extract were calculated using Equation (1).

$$
\text { PPL Activity (PPLA) }=\frac{\left[\mathrm{C}_{\mathrm{p}-\mathrm{NP}}\right]}{\mathrm{t}_{\mathrm{R}}}
$$

Where $\left[\mathrm{C}_{\mathrm{p}-\mathrm{NP}}\right]$ denotes of $\mathrm{p}$-nitrophenyl released from $\mathrm{p}$-NPP by $1 \mathrm{~mL}$ of PPL at $37{ }^{\circ} \mathrm{C}(\mu \mathrm{mol})$ and $t_{R}$ denotes of the reaction time (min). Then, the percentage of inhibition (PI) was determined by using Equation (2).

$$
\mathrm{PI}(\%)=\frac{\left[\mathrm{PPLA}_{\mathrm{w} / \mathrm{o}}\right]-\left[\mathrm{PPLA}_{\mathrm{w}}\right]}{\left[\mathrm{PPLA}_{\mathrm{w} / \mathrm{o}}\right]}
$$

Where $\left[\mathrm{PPLA}_{\mathrm{w} / \mathrm{o}}\right]$ denotes of the standard PPL activity without Aquilaria crude extract $(\mu \mathrm{mol} / \mathrm{mL} \cdot \mathrm{min})$ and $\left[\mathrm{PPLA}_{\mathrm{w}}\right]$ denotes of the sample PPL activity with Aquilaria crude extract ( $\mu \mathrm{mol} / \mathrm{mL} . \mathrm{min})$.

\subsection{Evaluation of Pancreatic Lipase Inhibition Kinetics}

The kinetics analysis of PPL activity inhibited by $A$. malaccensis and A. subintegra leaves crude extracts was determined by using the graphical method via. double reciprocal (Lineweaver-Burk) plots. The plots were constructed at different $p$-NPP concentration varying from 100 to $1000 \mu \mathrm{M} / \mathrm{mL}$ for the PPL reaction with and without Aquilaria crude extract (control). The mode of inhibition was determined by looking at the pattern of interception and crossing of linear lines for the reciprocal data of PPL activity with and without inhibition vs. $p$-NPP concentration. All kinetic parameters which are the Michaelis-Menten constant $\left(K_{m}\right)$ and the maximum reaction rate or enzyme activity $\left(V_{m}\right)$, were obtained from the reciprocal of Michaelis-Menten Equation (3), which given by Equation (4), wherein the $V_{m}$ was calculated from the interception at $\mathrm{y}$-axis and $K_{m}$ was calculated from the slope of the linear graph. The inhibition constant $\left(K_{i}\right)$ was calculated by substituting $K_{m}$ and $V_{m}$ in the Michaelis-Menten kinetic equation (Equation 5), which was modified by taking the additional terms of $K_{i}$ in the reaction into account when the mode of inhibition has been identified from the Lineweaver-Burk plot.

$$
\begin{aligned}
& V=\frac{V_{m}[S]}{K_{m}+[S]} \\
& \frac{1}{V}=\frac{K_{m}}{V_{M}} \frac{1}{[S]}+\frac{1}{V_{m}}
\end{aligned}
$$

\section{Results and Discussion}

3.1 Content of Gallic acid and Quercetin in Ultrasonicated Aquilaria Leaves Crude Extract of Different Particle Sizes

The content of gallic acid and quercetin in A. malaccensis and A. subintegra crude extracts of different particle size of ultrasonicated leaves is shown in Figure 1. It was found that, the highest concentration of gallic acid and quercetin determined in both Aquilaria leaves crude extracts was at the particle size of 250 $\mu \mathrm{m}$. This indicates that the total phenolic and flavonoid were significantly increased with decreasing particle size [21]. The particle size re- 
duction of material from plant has turned into a fundamental viewpoint, where it has a significant effect in the extraction of active compounds, in which it provides a shorter mass transfer distance for the extraction solvent to travel and also more surface area were available for molecular transport [22-24]. It was also found that the extensive mass transfer of solute between phases also decreased the time for maximum phytochemical content to be extracted [25]. Furthermore, sample with larger particle size will have a smaller surface area which would restricted the solubility of water soluble components and led to decrease in the values of total phenolic and flavonoid content [26]. The aid of pretreatment method by using ultrasonication also contribute a significant effect, where the current particle size of leaves was reduced proportionally to the duration of time in this process, which leads to a reduction of particle diameter resulted by the cavitation energy generated by ultrasound, that raised local pressure changed and shifted in liquid which resulting in damaged on the particle [27]. There-

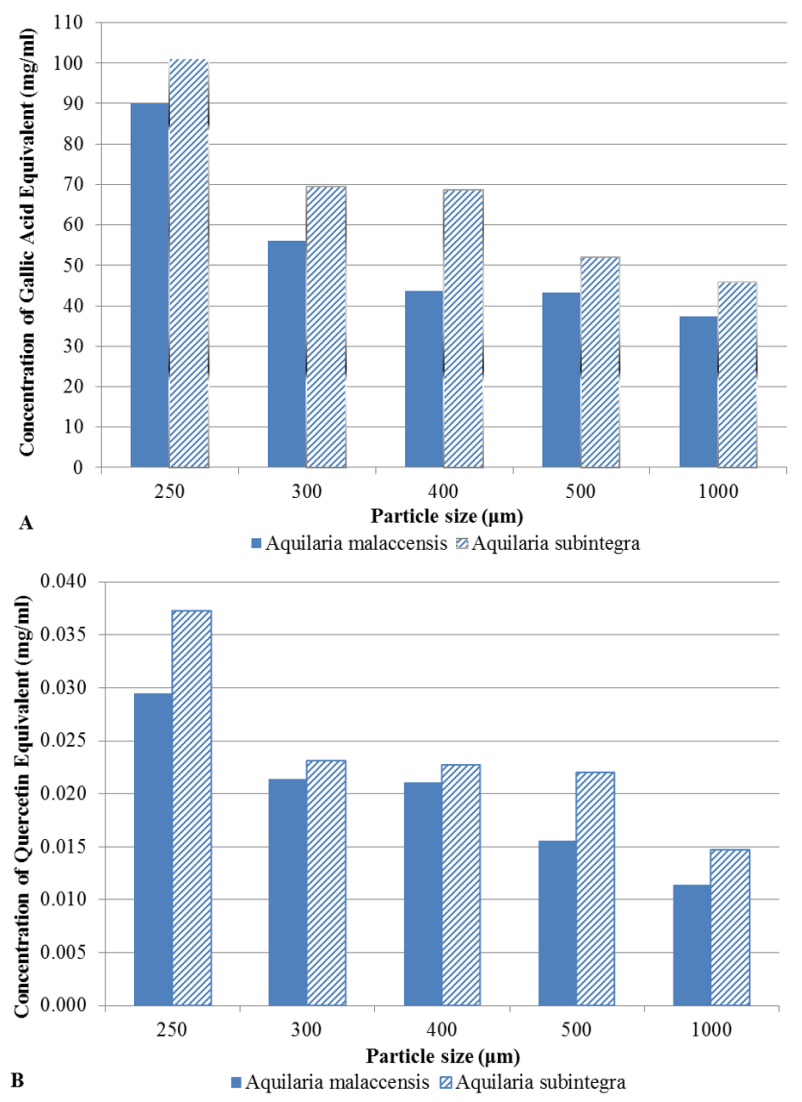

Figure 1. A) Gallic Acid and B) Quercetin concentration in the crude extract of $A$. malaccensis and A. subintegra at different particle sizes of leaves after ultrasonication process at $60{ }^{\circ} \mathrm{C}$ for 30 minutes. fore, optimization efforts on the ultrasonication process, specifically on the reduction of particle size, can be rationally developed with the presence of the quantification of such heuristic rules for each plant source [25]. The sample matrix, the particle size and the extraction technique also were strongly influence the phenolic and flavonoid extraction [28]. It was found that the concentration of gallic acid and quercetin equivalent in A. subintegra crude extract were $10 \%$ and $20 \%$ higher than the concentration of gallic acid and quercetin equivalent in A. malacensis crude extract.

3.2 In-vitro Inhibitory effect of Ultrasonicated Aquilaria Leaves Crude Extract at Different Particle Sizes on Pancreatic Lipase

Figure 2 shows the percentage inhibition of porcine pancreatic lipase (PPL) by A. malaccensis and A. subintegra leaves crude extract that was calculated by using Equation (2) for particle sizes range of $250,300,400,500$, and $1000 \mu \mathrm{m}$. The highest percentage of PPL inhibition was given by the crude extract from leaves with particle size of $250 \mu \mathrm{m}$ for both Aquilaria species. The percentage of PPL inhibition increased as the content of gallic acid and quercetin equivalent in the crude extract of different particle size increased. The result is in line with research done using green tea powders, wherein the inhibition depends on the content of phenolic and flavonoid of different particle size in the leaves [29]. The results obtained also revealed that antioxidant activity was dependent on particle size of powders [29]. Thus, it shows that smaller particle size leads to higher percentage of pancreatic lipase inhibi-

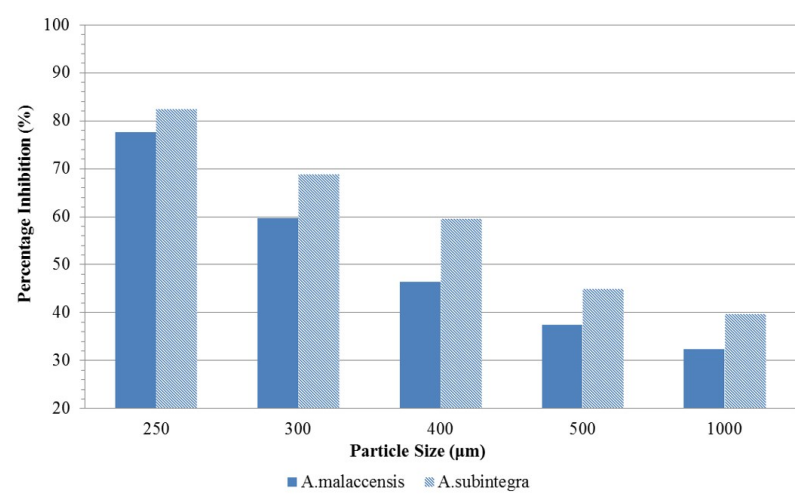

Figure 2. Percentage Inhibition of PPL by $A$. malaccensis and A. subintegra leaves crude extract for different particle sizes. 
tion, due to the total phenolic and flavonoid content in the sample. The percentage of PPL inhibition was higher for A. subintegra compared to A. malaccensis, due to the content of gallic acid and quercetin equivalent were higher in the $A$. subintegra crude extract.

3.3 Kinetic Inhibition of Ultrasonicated Aquilaria Leaves Crude Extract at Different Particle Sizes

The mode of PPL inhibition exhibits by the Lineweaver-Burk plots of different particle size of ultrasonicated A. malaccensis and A. subintegra leaves was found to be mixed-inhibition (Figures 3 and 4), which shows that Aquilaria extract was able to bind to free PPL and also to PPL- $p$-NPP complex. Based on the mode of inhibition identified, the overall inhibition reaction mechanism of mixed-inhibition featured by $A$. malaccensis and A. subintegra leaves crude extract is shown in Equation (5). Based on the reaction mechanism, both gallic acid and quercetin equivalent in Aquilaria crude extracts bound to PPL and to PPL- $p$-NPP complex, and there were possibilities for these in-

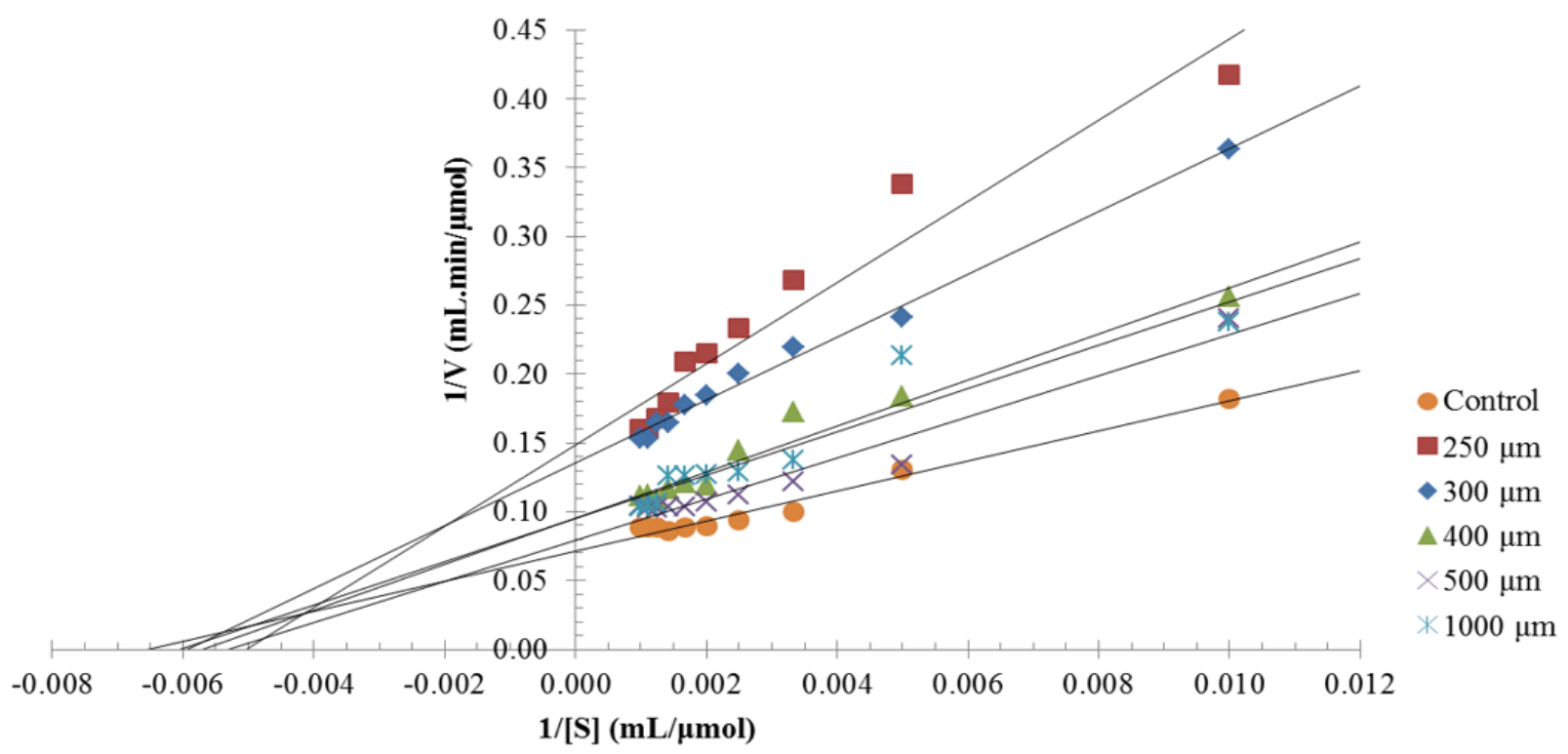

Figure 3. Lineweaver-Burk plots of PPL with and without A.malaccensis leaves crude extract for particle size of $250,300,400,500$ and $1000 \mu \mathrm{m}$.

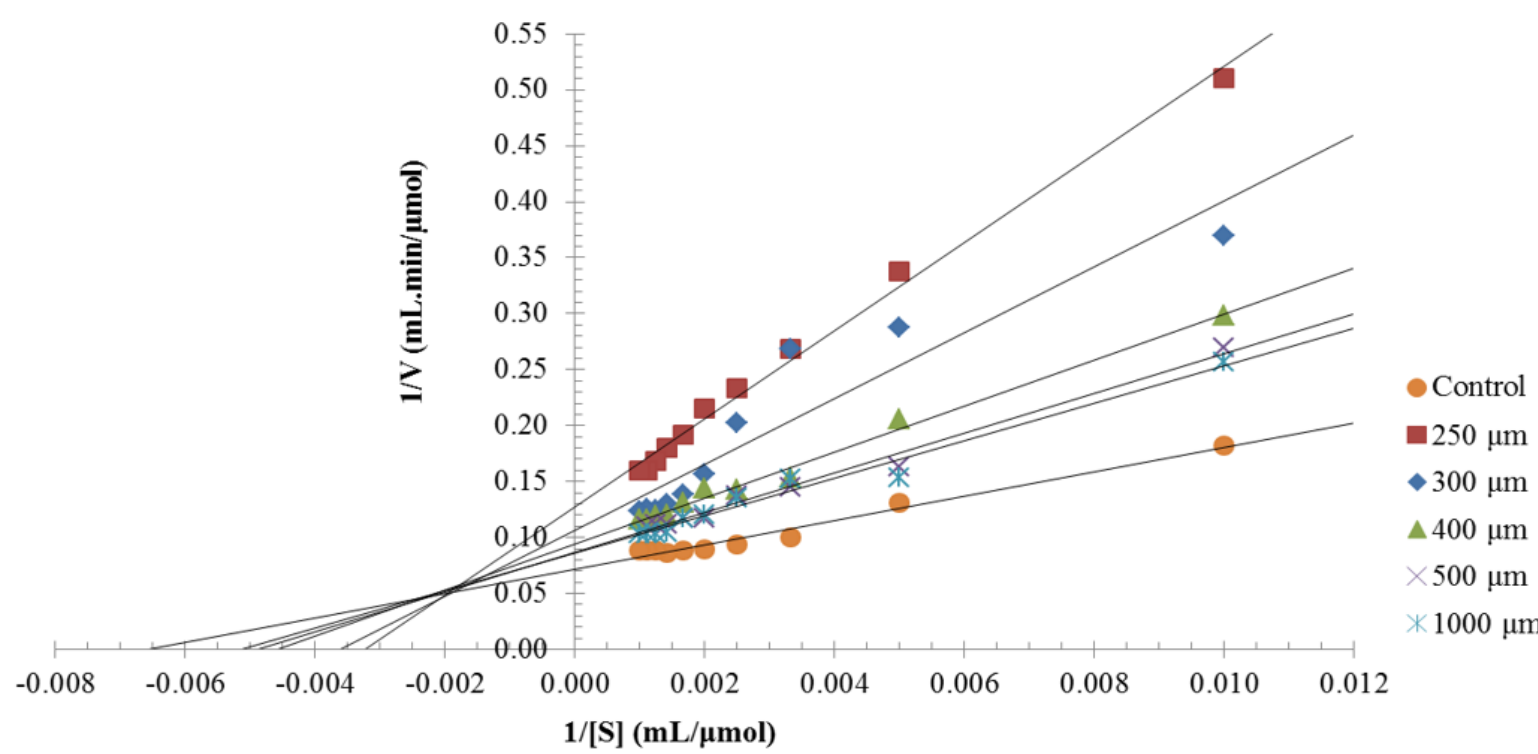

Figure 4. Lineweaver-Burk plots of PPL with and without $A$. subintegra leaves crude extract for particle size of $250,300,400,500$ and $1000 \mu \mathrm{m}$. 


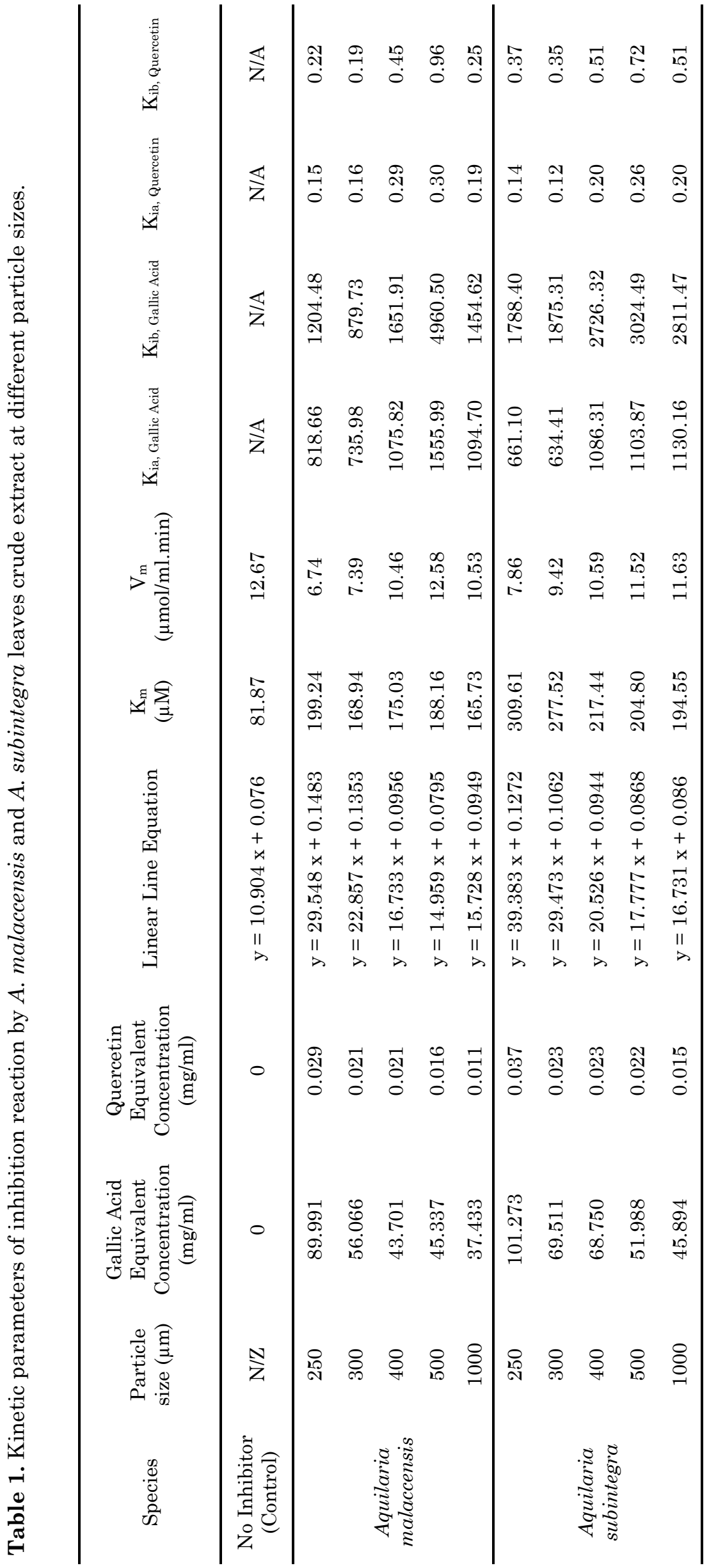


hibitors to bind at both state of PPL at the same time. In mixed-inhibition, the inhibitor is capable of binding to both the free enzyme and to the enzyme-substrate complex [30].

The linear line equation of Lineweaver-Burk plot (Equation 4) is the reciprocal of MichaelisMenten Equation (3), wherein it can be written as Equation (6) to represent the overall PPL inhibition reaction by Aquilaria extract. The kinetic parameters which are the MichaelisMenten constant $\left(K_{m}\right)$, maximal velocity $\left(V_{m}\right)$ and inhibition constant $\left(K_{i a}\right.$ and $K_{i b}$ ) for the mixed-type of inhibition reaction were calculated by using Equation (4) and (6). By referring to the overall reaction mechanism of Aquilaria extract shown in Equation (5), $K_{i a}$ is the inhibition constant for binding of Aquilaria extract to the PPL and $K_{i b}$ is the inhibition constant for binding of Aquilaria extract to the PPL- $p$-NPP complex. All calculated values of kinetic parameter were tabulated in Table 1.

Based on the linear line equation obtained from the Lineweaver-Burk plots (Table 1), the interception at y-axis of the plot presented the value of $1 / V_{m}$, where $V_{m}$ was calculated from this reciprocal value. The slope of the graph presented the value of $K_{m} / V_{m}$, which is also known as specificity time [31]. Thus, the value of $K_{m}$ was calculated by substituting the value of $V_{m}$ which was formerly obtained from the yaxis interception. Therefore, in inhibition study, the $K_{m}$ and $V_{m}$ in Equation (4) was referred to the $K_{m}$ and $V_{m}$ value of inhibition, which can also be denoted as $K_{m, a p p}$ and $V_{m, a p p}$. In inhibition reaction, Equation (6) shows that the slope of $K_{m} / V_{m}$ was decreased by a factor of $\left\{1+\left[\right.\right.$ Aqila Extract] $\left./ K_{i a}\right\}$, due to the inhibitory effect given by Aquilaria extract. In order to show that $K_{m}$ and $V_{m}$ were affected by Aquilaria crude extract and not by $p$-NPP, thus Equation (4) and Equation (6) was correlated and rearranged to obtain Equation (7) and (8), in which later it can be used to calculate $K_{i a}$ and $K_{i b}$, where [Aquilaria Extract] was the concentration of gallic acid and quercetin equivalent in the Aquilaria crude extract.

The value of $V_{m}$ also decreased because Aquilaria crude extract was proficient to prevent catalysis regardless of whether $p$-NPP was attached to PPL during the state of PPL- $p$-NPP complex (Equation 5). With mixed-type inhibitors in the reaction, the $K_{m}$ varied with the relative values of $K_{i a}$ and $K_{i b}$, wherein the value of $K_{m}$ increased as the $K_{i a}$ or $K_{i b}$ value decreased. Moreover, in mixed-inhibition, the dissociation constant of inhibitor binding at free PPL was differed from the dissociation constant for binding at PPL- $p$-NPP complex. The value of $K_{i}$ for an inhibitor is analogous to $K_{m}$ for a substrate, where it reflects the strength of the interaction between the PPL and Aquilaria crude extracts at the state with or without $p$-NPP. A small $K_{i}$ value reflects the tight binding of an inhibitor to an enzyme, whereas a larger $K_{i}$ value reflects the weaker binding. The results found that the $K_{i b}$ value was higher than $K_{i a}$, in which this indicates that the affinity of inhibitor bound to free PPL was higher than the binding of inhibitor to PPL- $p$-NPP complex, which makes the inhibitory effect stronger. Yet, according to the Federation of European Biochemical Societies, the case in which $K_{i a}$ is lower than $K_{i b}$ are known as predominantly competitive inhibition [32]. Furthermore, the presence of $p$-NPP on PPL has no influence on the ability of a mixed type inhibitor to bind to PPL because even though it does not have structural similarity to $p$-NPP, it was able to bind to both the free PPL and the PPL- $p$-NPP complex. Although the binding is away from the active site, it can still alter the conformation of the enzyme and reduce its catalytic activity due to changes in the nature of the catalytic groups at the active site [33].

Similar inhibition mode is also observed in the pancreatic lipase inhibition study done by Ong et al. using the extracts of Eleusine indica (L.) Gaertner [34]. It indicates the possibility of pancreatic lipase-substrate complex formation with the inhibitor binding at a distinct site from the active site resulting in reduction in complex affinity. Thus, this explained the increase in $K_{m}$ for the inhibition of PPL by using the crude extract from ultrasonicated Aquilaria leaves. In the inhibition by A. subintegra crude extract, it was found that the effect of mixed-inhibition was a reduction in $V_{m}$ and decrement in $K_{m}$ as the particle size of leaves increased.

However, $K_{m}$ for PPL inhibition by $A$. $m a$ laccensis crude extract increased for the particle size of 400 and $500 \mu \mathrm{m}$ which indicates that the affinity between PPL and $p$-NPP was lower, regardless to the content of the gallic acid and quercetin equivalent in $A$. malaccensis crude extracts. The sudden increment of $V_{m}$ at $500 \mu \mathrm{m}$ of $A$. malaccensis leaves was due to the higher PPL activity at lower $p$-NPP concentration compared to PPL activity at higher $p$-NPP concentration (Figure 3). Thus, it can be concluded that a larger value of $K_{m}$ shows a weak binding of substrate to enzyme [35]. The 


$$
\begin{aligned}
& \text { PPL } \quad+p \text {-NPP } \leftrightarrow \text { PPL- }(p \text {-NPP) } \leftrightarrow \text { PPL }+p \text {-NP }+ \text { Palmitate } \\
& K_{m, a p p}=K_{m} \frac{1+\frac{[\text { Aquilaria } \text { Extract }]}{K_{i a}}}{1+\frac{[\text { Aquilaria } \text { Extract }]}{K_{i b}}}
\end{aligned}
$$

change in $K_{m}$ also might varies, and it is depend on the relative values of inhibition constant at free enzyme $\left(K_{i a}\right)$ and inhibition constant at enzyme-substrate complex $\left(K_{i b}\right)$.

\section{Conclusions}

Based on the results obtained, it turns out that the smallest particle size of leaves which was $250 \mu \mathrm{m}$, that have been soaked for 24 hours with a ratio of $1: 100(\mathrm{w} / \mathrm{v})$ and ultrasonicated at $60^{\circ} \mathrm{C}$ for 30 minutes resulted the highest content of gallic acid and quercetin equivalent in Aquilaria crude extract, as well as giving the highest percentage of inhibition towards PPL. It was proven that smallest particle size provides a great effect in obtaining higher gallic acid and quercetin content in the crude extract. The lowest PPL activity was found in the inhibition reaction using Aquilaria crude extract from $250 \mu \mathrm{m}$ particle size of leaves. The existence of gallic acid and quercetin equivalent in the crude extracts had contributed to the inhibition of PPL, with the highest percentage PPL inhibition of $82 \%$ for $1 \mathrm{~mL}$ of Aquilaria crude extract used. The percentage of PPL inhibition could be increased with increasing volume of Aquilaria crude extract used. Studies on kinetics were initiates by identifying the mode of inhibition presented by Aquilaria against PPL using Lineweaver-Burk kinetic plot. The mode of inhibition identified for the sample with highest content of gallic acid and quercetin equivalent was mixedinhibition. In this type of inhibition, the value of $K_{m}$ was higher and $V_{m}$ was lower compared to the value of $K_{m}$ and $V_{m}$ for the non-inhibited PPL. It indicates that this reversible inhibitor decreased the rate of PPL activity and also reduced the affinity between $p$-NPP and PPL to react. Furthermore, it is believed that the pancreatic lipase has the other site than the active site for both the $p$-NPP and inhibitor in Aquilaria crude extract to bind. The inhibition constant for mixed-inhibition were known as $K_{i a}$ and $K_{i b}$, wherein these two constants had different values with one was higher to the other one. Lower value of $K_{i a}$ indicates that the affinity between inhibitors in Aquilaria leaves crude extract and free PPL was higher. The inhibitor activity and kinetic parameters determined from Aquilaria spp. is expected to benefit in controlling obesity and also problems associated with excess weight. Besides, it can further increase the potential of widely planted and wildly grown Aquilaria species. It is expected that this study will extend the knowledge on enzyme inhibition kinetics and all related parameters that may able to help in identifying the level of effectiveness of an inhibitor that would also benefits the relevant research in this area. 


\section{Acknowledgement}

The authors would like to acknowledge Universiti Teknologi MARA (UiTM) and INQKA UiTM for awarding research grant Biocatalysis and Biobased Materials Tech Research Group 600-RMI/DANA 5/3/REI (0009/2016), allocating budget for this journal and providing facilities to conduct this research. Authors also thankful to the staff of Faculty of Chemical Engineering, Universiti Teknologi MARA, Shah Alam for their help in performing laboratory work.

\section{References}

[1] Kim, G.W., Lin, J.E., Blomain, E.S., Waldman, S.A. (2014). Antiobesity pharmacotherapy: new drugs and emerging targets. Clinical Pharmacology Theraphy, 95, 53-66. DOI: 10.1038/clpt.2013.204

[2] Sun, N.N., Wu, T.Y., Chau, C.F. (2016). Natural Dietary and Herbal Products in AntiObesity Treatment. Molecules, 21(10), 1-15. DOI: $10.3390 /$ molecules21101351

[3] Kim, G.W., Lin, J.E., Blomain, E.S., Waldman, S.A. (2013). New Advances in Models and Strategies for Developing Anti- Obesity Drugs Obesity Drugs. Expert Opinion on Drug Discovery, 8(6), 655-671. DOI: 10.1517/17460441.2013.792804

[4] Bogarin, R., Chanoine, J.P. (2009). Efficacy, Safety and Tolerability of Orlistat, a Lipase Inhibitor, in the Treatment of Adolescent Weight Excess. Therapy, 6(1), 23-30. DOI: 10.2217/14750708.6.1.23

[5] Rani, N., Vasudeva, N., Sharma, S.K. (2012). Quality Assessment and Anti-Obesity Activity of Stellaria media (Linn.) Vill. BMC Complementary and Alternative Medicine, 12:145, 18. DOI: $10.1186 / 1472-6882-12-145$.

[6] Palhares, R.M., Drummond, M.G., Dos Santos Alves Figueiredo Brasil, B., Cosenza, G.P., Das Graças Lins Brandão, M., Oliveira, G. (2015). Medicinal Plants Recommended by the World Health Organization: DNA Barcode Identification Associated with Chemical Analyses Guarantees Their Quality. PLoS ONE, $10(5), \quad 1-29 . \quad$ D O I : 10.1371/journal.pone.0127866

[7] Gondoin, A., Grussu, D., Stewart, D., McDougall, G.J. (2010). White and Green Tea Polyphenols Inhibit Pancreatic Lipase In Vitro. Food Research International, 43(5), 15371544. DOI: 10.1016/j.foodres.2010.04.029

[8] Villa-Ruano, N., Zurita-Vásquez, G.G., Pacheco-Hernández, Y., Betancourt-Jiménez, M.G., Cruz-Durán, R., Duque-Bautista, H. (2013). Anti-lipase and Antioxidant Properties of 30 Medicinal Plants used in Oaxaca,
México. Biological Research, 46(2), 153-160. DOI: 10.4067/S0716-97602013000200006

[9] Adisakwattana, S., Intrawangso, J., Hemrid, A., Chanathong, B., Mäkynen, K. (2012). Extracts of Edible Plants Inhibit Pancreatic Lipase, Cholesterol Esterase and Cholesterol Micellization, and Bind Bile Acids. Food Technology and Biotechnology, 50(1), 11-16.

[10] Md Salehan, N.A., Sulaiman, A.Z., Ajit, A. (2016). Effect of temperature and sonication on the extraction of gallic acid from Labisia Pumila (Kacip Fatimah). ARPN Journal of Engineering and Applied Sciences, 11(4), 2193-2198.

[11] Gam, D.H., Kim, S.Y., Kim, J.W. (2020). Optimization of Ultrasound-Assisted Extraction Condition for Phenolic Compounds, Antioxidant Activity, and Epigallocatechin Gallate in Lipid-Extracted Microalgae. Molecules, 25(3), 1-17. DOI: 10.3390/molecules25030454

[12] Zhu, Y., Yu, J., Jiao, C., Tong, J., Zhang, L., Chang, Y., Sun, W., Jin, Q., Cai, Y. (2019). Optimization of Quercetin Extraction Method in Dendrobium Officinale by Response Surface Methodology. Heliyon, 5(9), e02374. DOI: 10.1016/j.heliyon.2019.e02374

[13] Liu, T.T., Liu, X.T., Chen, Q.X., Shi, Y. (2020). Lipase Inhibitors for Obesity: A Review. Biomedicine and Pharmacotherapy, 128, 1-9. DOI : 10.1016/j.biopha.2020.110314

[14] Jawad Kadhim, N., Sareea Al-Rekaby, L., Abdul Redha, A., Chappell, J. (2019). Chemical Composition and Antioxidant Capacity of Eggplant Parts during Vegetative and Flowering Stage. Journal of Physics: Conference Series, $1294(9), \quad 1-9$. D O I : 10.1088/17426596/1294/9/092013

[15] Hatami, T., Emami, S. A., Miraghaee, S. S., Mojarrab, M. (2014). Total Phenolic Contents and Antioxidant Activities of Different Extracts and Fractions from the Aerial Parts of Artemisia Biennis Willd. Iranian Journal of Pharmaceutical Research, 13(2), 551-558. DOI: https://doi.org/10.22037/ijpr.2014.1518

[16] Stanković, M.S. (2011). Total phenolic content, flavonoid concentration and antioxidant activity of Marrubium peregrinum L. Extracts. Kragujevac Journal of Science, 33, 6372 .

[17] Singleton, V.L., Orthofer, R., LamuelaRaventós, R.M. (1999). Analysis of total phenols and other oxidation substrates and antioxidants by means of Folin-Ciocalteu reagent. Methods Enzymol., 299, 152-178.

[18] Shah, M.D., Hossain, M.A. (2014). Total Flavonoids Content and Biochemical Screening of the Leaves of Tropical Endemic Medicinal 
Plant Merremia Borneensis. Arabian Journal of Chemistry, 7(6), 1034-1038. DOI: 10.1016/j.arabjc.2010.12.033

[19] Ozgen, M., Attar, A., Elalmis, Y., Birbir, M., Yucel, S. (2016). Enzymatic Activity of a Novel Halotolerant Lipase from Haloarcula Hispanica 2TK2. Polish Journal of Chemical Technology, 18(2), 20-25. DOI: 10.1515/pjct2016-0024

[20] Bustanji, Y., Al-Masri, I.M., Mohammad, M., Hudaib, M., Tawaha, K., Tarazi, H., Alkhatib, H.S. (2011). Pancreatic Lipase Inhibition Activity of Trilactone Terpenes of Ginkgo Biloba. Journal of Enzyme Inhibition and Medicinal Chemistry, 26(4), 453-459. DOI: 10.3109/14756366.2010.525509

[21] Samavardhana, K., Supawititpattana, P., Jittrepotch, N., Rojsuntornkitti, K., Kongbangkerd, T. (2015). Effects of Extracting Conditions on Phenolic Compounds and Antioxidant Activity from Different Grape Processing Byproducts. International Food Research Journal, 22(3), 1169-1179.

[22] Bucić-Kojić, A., Planinić, M., Tomas, S., Bilić, M., Velić, D. (2007). Study of Solid-Liquid Extraction Kinetics of Total Polyphenols from Grape Seeds. Journal of Food Engineering, 81 ( 1 ), $\quad 236-242$. D O I : 10.1016/j.jfoodeng.2006.10.027

[23] Qu, W., Pan, Z., Ma, H. (2010). Extraction Modeling and Activities of Antioxidants from Pomegranate Marc. Journal of Food Engineering, $99(1), \quad 16-23$. DO I: 10.1016/j.jfoodeng.2010.01.020

[24] Saleh, I.A., Kamal, S.A., Shams, K.A., AbdelAzim, N.S., Aboutabil, E.A., Hammouda, F.M. (2015). Effect of Particle Size on Total Extraction Yield and Silymarin Content of Silybum marianum L. Seeds. Research Journal of Pharmaceutical, Biological and Chemical Sciences, 6(2), 803-809.

[25] Gião, M.S., Pereira, C.I., Fonseca, S.C., Pintado, M.E., Malcata, F.X. (2009). Effect of Particle Size Upon the Extent of Extraction of Antioxidant Power from the Plants Agrimonia Eupatoria, Salvia sp. and Satureja montana. Food Chemistry, 117(3), 412-416. DOI: 10.1016/j.foodchem.2009.04.020
[26] Norhidayah, A., Noriham, A., Rusop, M. (2013). Changes in Physical and Antioxidant Properties of Nano Structured Zingiber Officinale (Ginger) Rhizome as Affected by Milling Time. Advanced Materials Research, 667, $\begin{array}{lllllllllll} & 4 & 4 & - & 1 & 4 & 9 & \text {. } & \text { D } & \text { O } & \text { I }\end{array}$ 10.4028/www.scientific.net/AMR.667.144

[27] Sumari, S., Roesyadi, A., Sumarno, S. (2013). Effects of Ultrasound on the Morphology, Particle Size, Crystallinity, and Crystallite Size of Cellulose. Scientific Study and Research: Chemistry and Chemical Engineering, Biotechnology, Food Industry, 14(4), 229-239.

[28] Khoddami, A., Wilkes, M.A., Roberts, T.H. (2013). Techniques for analysis of plant phenolic compounds. Molecules, 18(2), 23282375. DOI: $10.3390 /$ molecules 18022328

[29] Zaiter, A., Becker, L., Karam, M.C., Dicko, A. (2016). Effect of Particle Size on Antioxidant Activity and Catechin Content of Green Tea Powders. Journal of Food Science and Technology, 53(4), 2025-2032. DOI: $10.1007 / \mathrm{s} 13197-016-2201-4$

[30] Kenakin, T.P. (2012). Chapter 6 - Enzymes as Drug Targets. In: Pharmacology in Drug Discovery Understanding Drug Response, 105-124.

[31] Cornish-Bowden, A. (2012). Fundamentals of Enzyme Kinetics, Wiley-Blackwell, 51.

[32] Symbolism and terminology in enzyme kinetics. Recommendations 1981. Biochem. J. 213 ( 3 ): $561-571$. D O I : https://doi.org/10.1042/bj2130561

[33] Sharma, R. (2012). Enzyme Inhibition: Mechanisms and Scope, Enzyme Inhibition and Bioapplications, IntechOpen, DOI: $10.5772 / 39273$.

[34] Ong, S.L., Mah, S.H., Lai, H.Y. (2016). Porcine Pancreatic Lipase Inhibitory Agent Isolated from Medicinal Herb and Inhibition Kinetics of Extracts from Eleusine indica (L.) Gaertner. Journal of Pharmaceutics, 2016, 19. DOI: $10.1155 / 2016 / 8764274$

[35] Buchholz, K., Kasche, V., Bornscheuer, U.T. (2012). Biocatalyst and Enzyme Technology, Second Edition, Wiley-Blackwell, Wiley-VCH Verlag \& Co. KGaA., 59-63.

Selected and Revised Papers from International Symposium of Green Engineering and Technology 2019 (ISGET 2019) (https://isget.uitm.edu.my/) (UiTM Malaysia, by September $5^{\text {th }}$ - ${ }^{\text {th }}$, 2019) after Peer-reviewed by Scientific Committee of ISGET 2019 and Peer-Reviewers of Bulletin of Chemical Reaction Engineering \& Catalysis. 